\title{
Altered diastolic function and aortic stiffness in Alzheimer's disease
}

This article was published in the following Dove Press journal:

Clinical Interventions in Aging

16 July 2014

Number of times this article has been viewed

\author{
Ali Nazmi Çalık ${ }^{3}$ \\ Kazım Serhan Özcan ${ }^{4}$ \\ Gülbün Yüksel ${ }^{2}$ \\ Barış Güngör' \\ Emre Aruğarslan' \\ Figen Varlibas ${ }^{2}$ \\ Ahmet Ekmekci' \\ Damirbek Osmonov' \\ Mustafa Adem Tatlısu' \\ Mehmet Karaca' \\ Osman Bolca' \\ İzzet Erdinler' \\ 'Department of Cardiology, \\ Siyami Ersek Cardiovascular and \\ Thoracic Surgery Center, Istanbul, \\ Turkey; ${ }^{2}$ Department of Neurology, \\ Haydarpașa Numune Training and \\ Research Hospital, Istanbul, Turkey; \\ ${ }^{3}$ Department of Cardiology, Yozgat \\ State Hospital, Yozgat, Turkey; \\ ${ }^{4}$ Department of Cardiology, Derince \\ Training and Research Hospital, \\ Kocaeli, Turkey
}

Correspondence: Ali Nazmi Çalık

Department of Cardiology, Yozgat State Hospital, Tașköprü Mahallesi, Hastane

Caddesi, Merkez, 66100 Yozgat, Turkey

$\mathrm{Tel}+905059200344$

$+902163432853$

Fax +90 216 56I3837

Email calik_nazmi@hotmail.com
Background: Alzheimer's disease (AD) is closely linked to cardiovascular risk factors.

Methods: Echocardiographic studies were performed, including left ventricular diastolic functions, left and right atrial conduction times, and arterial stiffness parameters, namely stiffness index, pressure-strain elastic modulus, and distensibility, on 29 patients with AD and 24 age-matched individuals with normal cognitive function.

Results: The peak mitral flow velocity of the early rapid filling wave (E) was lower, and the peak velocity of the late filling wave caused by atrial contraction (A), deceleration time of peak E velocity, and isovolumetric relaxation time were higher in the $\mathrm{AD}$ group. The early myocardial peak $\left(\mathrm{E}_{\mathrm{a}}\right)$ velocity was significantly lower in $\mathrm{AD}$ patients, whereas the late diastolic $\left(\mathrm{A}_{\mathrm{a}}\right)$ velocity and $\mathrm{E} / \mathrm{E}_{\mathrm{a}}$ ratio were similar between the two groups. In Alzheimer patients, stiffness index and pressure-strain elastic modulus were higher, and distensibility was significantly lower in the $\mathrm{AD}$ group compared to the control. Interatrial electromechanical delay was significantly longer in the $\mathrm{AD}$ group.

Conclusion: Our findings suggest that patients with $\mathrm{AD}$ are more likely to have diastolic dysfunction, higher atrial conduction times, and increased arterial stiffness compared to the controls of same sex and similar age.

Keywords: diastolic dysfunction, atrial conduction time

\section{Introduction}

Dementia is defined as a decline in cognitive function that is associated with an impaired function in daily life. ${ }^{1}$ The most common form of dementia is Alzheimer's disease (AD), which represents about $70 \%$ of cases. ${ }^{2} \mathrm{AD}$ can be identified as a gradually progressive dementia of insidious onset, which occurs in the absence of other diseases that could be responsible for the cognitive deficits. Although certain diagnostic criteria emphasize that $\mathrm{AD}$ is a diagnosis of exclusion with regard to vascular disease, vascular factors may also have a role in late-onset AD. ${ }^{1,2}$

Previous studies suggest that there is a close relationship between AD, hypertension, diabetes, stroke, and atherosclerosis..$^{3-7}$ Some studies have investigated the parameters of arterial stiffness in patients with dementia. ${ }^{8-11}$ It has been observed that patients with AD have structural and functional heart abnormalities, including subclinical impairment of cardiac structure and function, aortic valve thickening, aortic regurgitation, and left ventricular (LV) wall motion abnormalities. ${ }^{12}$

In this study, our objective was to examine the LV diastolic parameters, atrial conduction times, and aortic stiffness parameters by conventional echocardiography in patients with and without $\mathrm{AD}$.

\section{Methods}

Patients attending the Haydarpaşa Numune Hospital Neurology Clinic, Istanbul, Turkey, were asked to volunteer for the study if they fulfilled the inclusion criteria 
for AD. The control group included age- and sex-matched individuals who had no cognitive decline. All patients and their carers read the information sheet provided before giving verbal and written consent to participate in the study. The echocardiographic examinations were performed in Siyami Ersek Cardiovascular and Thoracic Surgery Center, Istanbul, Turkey. The study was approved by the local ethics committee.

The diagnosis of $\mathrm{AD}$ was made according to the probable AD criteria proposed by the National Institute of Neurological and Communicative Disorders and Stroke and the Alzheimer's Disease and Related Disorders Association (NINCDS-ADRDA), ${ }^{13}$ as well as the Diagnostic and Statistical Manual of Mental Disorders, Fourth Edition. ${ }^{14}$

The control group participants were defined as having no demonstrable cognitively based limitations of activities of daily living, including employment, when applicable. Rigorous criteria were used to exclude anyone with any type of symptomatic or severe brain-related neurologic or psychiatric illness. This was done by prospective interview of the participant and careful scrutiny of the medical records. Examples of excluded conditions were mental retardation, epilepsy, cerebral infarction or hemorrhage, multiple sclerosis, brain tumors, major depressive disorders (unipolar or bipolar), schizophrenia, traumatic brain injuries, and substance abuse. Patients with more than mild mitral or aortic regurgitation and aortic or mitral stenosis were also excluded from the study. The nondemented (ND) participants were defined as having a Mini-Mental State Examination ${ }^{13,14}$ score of 28 or higher, a clinical dementia rating of 0 , and functional assessment staging score of 2 or lower.

\section{Echocardiography}

All echocardiographic evaluations were performed with a transducer of 2.5-3.5 MHz and a GE Vivid 3 echocardiography device (General Electric Company, Milwaukee, WI, USA). Each patient was evaluated with M-mode, twodimensional Doppler, and tissue Doppler echocardiography. Single-lead electrocardiography (ECG) recordings were made constantly during the workup. The end-diastolic and end-systolic diameters of the left ventricle (LV) as well as the end-systolic diameter of the left atrium (LA) were measured with M-mode echocardiography on the parasternal long axis view, in accordance with the American Society of Echocardiography guidelines. ${ }^{15}$ LA volume was calculated with the $(\mathrm{A} 1 \times \mathrm{A} 2 \times \mathrm{A} 3 \times 0.524)$ formula using the left atrial diameters measured from the parasternal long axis (anteroposterior-A1) and apical four-chamber (mediolateral-A2, apicobasal-A3) views. Mitral inflow velocities were evaluated by pulsed wave (PW) Doppler echocardiography with the sample volume placed at the tip of the mitral leaflets from the apical four-chamber view. Diastolic fillings were classified initially on the basis of the peak mitral flow velocity of the early rapid filling wave (E), peak velocity of the late filling wave caused by atrial contraction (A), E/A ratio, and deceleration time (DT), which is the time interval for the peak E velocity to reach zero baseline. Mitral inflow velocities were evaluated by pulsed wave (PW) Doppler echocardiography with the sample volume placed at the tip of the mitral leaflets from the apical four-chamber view. The LV cavity elongates, rotates, and expands laterally after myocardial relaxation. The longitudinal motion of the mitral annulus has been shown to correlate with the rate of myocardial relaxation. ${ }^{15}$ The velocity of the mitral annulus can be recorded by the LV-pulsed tissue Doppler imaging, which is an essential part of evaluation of diastolic function. Tissue Doppler imaging was performed in the apical four-chamber view using a $5 \mathrm{~mm}$ pulsed Doppler sample volume with as minimal optimal gain as possible to obtain the best signal-to-noise ratio. The signal filter of the spectral pulsed Doppler was adjusted until the Nyquist limit was $15-20 \mathrm{~cm} / \mathrm{s}$ using a transducer of 3.5-4.0 $\mathrm{MHz}$ in frequency and we used minimal optimal gain to perform the tissue Doppler echocardiography. The monitor sweep speed was set at $50-100 \mathrm{~mm} / \mathrm{s}$ to optimize the spectral display of myocardial velocities. On the apical four-chamber view, the PW Doppler cursor was placed on the lateral mitral annulus of the left ventricle, septal mitral annulus, and right ventricle's tricuspid annulus, respectively, to obtain tissue Doppler spectral images. The myocardial peak early $\left(\mathrm{E}_{\mathrm{a}}\right)$ and late diastolic $\left(\mathrm{A}_{\mathrm{a}}\right)$ velocities were obtained from these areas. All echocardiographic measurements were performed by the same observer. The time passing from the beginning of the $\mathrm{P}$ wave on ECG to the $\mathrm{A}_{\mathrm{a}}$ wave on tissue Doppler trace was accepted as the atrial conduction time. The atrial conduction times measured from mitral lateral (MT), mitral septal (MS), and tricuspid lateral (TL) annuli were named as ML-EMD (electromechanical delay), MS-EMD, and TL-EMD, respectively. The time difference between ML-EMD and TL-EMD was defined as the interatrial EMD.

We measured aortic diameters at a level $3 \mathrm{~cm}$ above the aortic cusps in long axis from the parasternal view. M-mode diameter measurements were made in systole (point of maximal anterior motion of aorta) and at end-diastole (Q wave on ECG). The means of three diameter measurements in sequential cardiac cycles were used for data analysis. Systemic arterial blood pressure (BP) was measured at 
the right brachial artery by manual sphygmomanometer with the patient supine using an adequately sized cuff. BP was measured three times on each occasion at 2-minute intervals and averaged. Pulse pressure (PP) was calculated by subtracting the diastolic BP from the systolic BP. Antihypertensive drugs were not discontinued on the day of the examination.

The elastic properties of the aorta were indexed by calculation of aortic distensibility (D), stiffness index (SI), and pressure-strain elastic modulus (Ep), and were as follows:

$$
\begin{aligned}
& \mathrm{D}=2(\mathrm{As}-\mathrm{Ad}) /(\mathrm{Ad}[\mathrm{Ps}-\mathrm{Pd}]), \\
& \mathrm{SI}=\ln (\mathrm{Ps} / \mathrm{Pd}) /([\mathrm{As}-\mathrm{Ad}] / \mathrm{Ad}),
\end{aligned}
$$

and

$$
\mathrm{Ep}=(\mathrm{Ps}-\mathrm{Pd}) /([\mathrm{As}-\mathrm{Ad}] / \mathrm{Ad})
$$

where As is aortic diameter at end-systole, Ad is aortic diameter at end-diastole, Ps is systolic BP, Pd is diastolic BP, and $\ln$ is natural logarithm. ${ }^{16-18}$

\section{Statistical analyses}

The continuous variables within group data were calculated as average \pm standard deviation, and categorical variables as numbers and percentages. Continuous variables were checked for the normal distribution assumption using Kolmogorov-Smirnov statistics. The Student's $t$-test was used for comparison of parametric variables and the categorical variables were tested by Pearson's $\chi^{2}$ test and Fisher's exact test. Binary logistic regression analysis was used to find the possible independent association between $\mathrm{AD}$ and study parameters. In multivariate regression analysis, aortic stiffness parameters were analyzed separately in order to prevent multicollinearity. $P$-values are two sided, and values $<0.05$ were considered statistically significant. All statistical studies were carried out using Statistical Package for Social Sciences (SPSS) software (v 16.0 for Windows; SPSS Inc., Chicago, IL, USA).

\section{Results}

A total of 53 individuals were enrolled: 29 in the AD group (12 male and 17 female; mean age \pm standard deviation, $76.8 \pm 5.2$ years) and 24 in the ND control group (14 female and ten male; mean age $77.1 \pm 6.7$ years). The age difference between the AD and ND groups was not statistically significant $(P=0.65)$. The characteristics of the study population are shown in Table 1. There were no significant differences between Alzheimer patients and controls regarding age, sex, body mass index, and risk factors, including hypertension, diabetes mellitus, and smoking status. Diastolic BP was lower and PP was higher in the patient group. Systolic BP measurements were similar. The mean duration of the disease was $3.5 \pm 1.9$ years in the AD group.

Echocardiographic parameters of the study groups are summarized in Table 2. LV diastolic and systolic diameters, LV ejection fraction, and LV mass were comparable between the two groups. LA anteroposterior diameters and LA volumes were significantly higher in the AD group $(P=0.01$, $P=0.01$, respectively). Mitral valve PW Doppler parameters were significantly different between the two groups, with lower E velocities and higher A velocities, DT, and IVRT in Alzheimer patients ( $P=0.01$ for each comparison). Mitral annular $\mathrm{E}_{\mathrm{a}}$ velocity was significantly lower in Alzheimer patients, whereas $\mathrm{A}_{\mathrm{a}}$ velocity and $\mathrm{E} / \mathrm{E}_{\mathrm{a}}$ ratio were similar

\begin{tabular}{|c|c|c|c|}
\hline Characteristics & $\begin{array}{l}\text { Patient group } \\
(n=29)\end{array}$ & $\begin{array}{l}\text { Control group } \\
(n=24)\end{array}$ & $P$-values \\
\hline Age (years), mean \pm SD & $76.8 \pm 5.2$ & $77.1 \pm 4.9$ & 0.65 \\
\hline Male/female, $\mathrm{n}$ & $12 / 17$ & $10 / 14$ & 0.98 \\
\hline $\mathrm{BMI}\left(\mathrm{kg} / \mathrm{m}^{2}\right)$, mean $\pm \mathrm{SD}$ & $26.8 \pm 5.3$ & $26.7 \pm 4.3$ & 0.91 \\
\hline Smoker (current), n (\%) & $2(6)$ & I (4) & 0.20 \\
\hline Hypertension, n (\%) & II (37) & $14(58)$ & 0.14 \\
\hline Diabetes mellitus, $\mathrm{n}(\%)$ & $4(13)$ & $4(16)$ & 0.77 \\
\hline Disease duration (years), mean $\pm S D$ & $3.5 \pm 1.9$ & - & - \\
\hline MMSE score, mean \pm SD & $18.9 \pm 3.3$ & $29.1 \pm 0.9$ & $<0.01 * *$ \\
\hline BP systolic $(\mathrm{mmHg})$, mean $\pm \mathrm{SD}$ & $139 \pm 13$ & $136 \pm 14$ & 0.43 \\
\hline BP diastolic $(\mathrm{mmH})$, mean $\pm \mathrm{SD}$ & $74 \pm 12$ & $82 \pm 13$ & $<0.05^{*}$ \\
\hline Pulse pressure $(\mathrm{mmHg})$, mean $\pm \mathrm{SD}$ & $65 \pm 7$ & $54 \pm 9$ & $<0.05^{*}$ \\
\hline
\end{tabular}
between the groups.

Table I Demographic characteristics and clinical and biochemical parameters of the study population

Notes: $* P<0.05, * * P<0.01$.

Abbreviations: BMI, body mass index; BP, blood pressure; MMSE, Mini-Mental State Examination; SD, standard deviation. 
Table 2 Conventional echocardiographic and left ventricular diastolic parameters of the study population

\begin{tabular}{|c|c|c|c|}
\hline $\begin{array}{l}\text { Echocardiographic } \\
\text { measurements }\end{array}$ & $\begin{array}{l}\text { Patient group } \\
(\mathrm{n}=29)\end{array}$ & $\begin{array}{l}\text { Control group } \\
(n=24)\end{array}$ & $P$-values \\
\hline LVDD, mm & $44.7 \pm 3.4$ & $44.9 \pm 3.1$ & 0.81 \\
\hline LVSD, mm & $26.6 \pm 3.6$ & $27.2 \pm 3.3$ & 0.52 \\
\hline IVS, mm & $9.1 \pm 1.4$ & $9.5 \pm 1.4$ & 0.35 \\
\hline $\mathrm{PW}, \mathrm{mm}$ & $9.1 \pm 1.1$ & $9.5 \pm 1.3$ & 0.21 \\
\hline LV mass, $g$ & $130.5 \pm 32.3$ & $139.4 \pm 33.9$ & 0.32 \\
\hline LV EF, \% & $62.2 \pm 3.1$ & $62.9 \pm 2.6$ & 0.41 \\
\hline LA anteroposterior diameter, $\mathrm{mm}$ & $42.1 \pm 2.4$ & $38.1 \pm 3.5$ & $<0.05^{*}$ \\
\hline LA volume, $\mathrm{cm}^{3}$ & $45.9 \pm 4.1$ & $37.8 \pm 7.1$ & $<0.05^{*}$ \\
\hline \multicolumn{4}{|l|}{ Mitral inflow parameters } \\
\hline $\mathrm{E}, \mathrm{cm} / \mathrm{s}$ & $52.3 \pm 9.1$ & $82.3 \pm 11.6$ & $<0.05^{*}$ \\
\hline $\mathrm{A}, \mathrm{cm} / \mathrm{s}$ & $107.7 \pm 14.1$ & $94.7 \pm 14.6$ & $<0.05^{*}$ \\
\hline LV DT, ms & $291.9 \pm 22.4$ & $221.1 \pm 18.9$ & $<0.05^{*}$ \\
\hline IRT, ms & $130 \pm 12.2$ & $105.2 \pm 9.8$ & $<0.05^{*}$ \\
\hline E/A ratio & $0.49 \pm 0.12$ & $0.93 \pm 0.08$ & $<0.05^{*}$ \\
\hline \multicolumn{4}{|l|}{ Tissue doppler parameters } \\
\hline$E_{a}, c m / s$ & $5.6 \pm 0.8$ & $8.3 \pm 0.9$ & $<0.05^{*}$ \\
\hline$A_{a}, \mathrm{~cm} / \mathrm{s}$ & $9.9 \pm 0.9$ & $9.6 \pm 0.8$ & $<0.05^{*}$ \\
\hline $\mathrm{E} / \mathrm{E}_{\mathrm{a}}$ & $9.7 \pm 2.7$ & $10.6 \pm 1.8$ & 0.17 \\
\hline
\end{tabular}

Notes: Data are expressed as mean \pm standard deviation. $* P<0.05$.

Abbreviations: A, peak velocity of the late filling wave caused by atrial contraction; $A_{a}$, late myocardial peak; DT, deceleration time; E, peak mitral flow velocity of the early rapid filling wave; $E$, early myocardial peak; $E F$, ejection fraction; IRT, isovolumic relaxation time; IVS, interventricular septum; LA, left atrium; LV, left ventricle; LVDD, left ventricular diastolic diameter; LVSD, left ventricular systolic diameter; PW, pulsed wave.

Diastolic BP was significantly lower and PP was significantly higher in $\mathrm{AD}$ patients. Aortic diameters, parameters of aortic stiffness, and atrial conduction times are reported in Table 3. Systolic aortic diameter was comparable between the groups; however, diastolic aortic diameter was significantly higher in the Alzheimer patients. SI (11.8 \pm 5.7 versus $3.3 \pm 1.1 ; P=0.01)$ and $\mathrm{Ep}(139.5 \pm 38.7$ versus $46.3 \pm 12.1 \mathrm{kPa}$; $P=0.01)$ were significantly higher, and $\mathrm{D}$ was significantly lower $\left(1.51 \pm 0.75\right.$ versus $\left.4.55 \pm 1.12 \quad 10^{-6} \mathrm{~cm}^{2} / \mathrm{dyn} ; P=0.01\right)$ in the $\mathrm{AD}$ group.
The atrial conduction times measured from the mitral valve's lateral (ML) and septal (MS) annuli were significantly higher in the Alzheimer patients. However, the conduction time measured from the TL annulus was similar between the $\mathrm{AD}$ and ND groups. The interatrial EMD was significantly higher in the $\mathrm{AD}$ group ( $16.1 \pm 11.1$ versus $10.5 \pm 6.4 \mathrm{~ms} ; P=0.03)$.

In univariate binary logistic regression analysis, $\mathrm{PP}$ (odds ratio [OR]: 1.18, 95\% confidence interval [CI]: 1.07-1.306; $P=0.01$ ), LA volumes (OR: $1.20,95 \%$ CI: $1.08-1.35 ; P=0.01$ ), interatrial EMD (OR: 1.07, 95\% CI: 1.01-1.146; $P=0.04$ ),

Table 3 Aortic stiffness parameters and atrial conduction times of the study population

\begin{tabular}{|c|c|c|c|}
\hline $\begin{array}{l}\text { Aortic stiffness parameters } \\
\text { and atrial conduction times }\end{array}$ & $\begin{array}{l}\text { Patient group } \\
(n=29)\end{array}$ & $\begin{array}{l}\text { Control group } \\
(n=24)\end{array}$ & $P$-values \\
\hline \multicolumn{4}{|l|}{ Aortic stiffness parameters } \\
\hline Systolic aortic diameter, mm & $36.3 \pm 3.7$ & $36.6 \pm 3.2$ & 0.73 \\
\hline Diastolic aortic diameter, $\mathrm{mm}$ & $34.1 \pm 3.9$ & $31.6 \pm 2.8$ & $<0.05^{*}$ \\
\hline Stiffness index & II. $8 \pm 5.7$ & $3.3 \pm 1.1$ & $<0.05^{*}$ \\
\hline Distensibility, $10^{-6} \mathrm{~cm}^{2} /$ dyn & $1.51 \pm 0.75$ & $4.55 \pm 1.12$ & $<0.05^{*}$ \\
\hline Elastic modulus, $\mathrm{kPa}$ & $139.5 \pm 38.7$ & $46.3 \pm 12.1$ & $<0.05^{*}$ \\
\hline \multicolumn{4}{|l|}{ Atrial conduction times } \\
\hline Mitral septal, ms & $67.1 \pm 6.3$ & $44.2 \pm 5.9$ & $<0.05^{*}$ \\
\hline ML, ms & $78.8 \pm 7.8$ & $52.1 \pm 6.7$ & $<0.05^{*}$ \\
\hline $\mathrm{TL}, \mathrm{ms}$ & $63.4 \pm 11.8$ & $59.5 \pm 9.5$ & 0.21 \\
\hline \multicolumn{4}{|l|}{ Atrial EMD time } \\
\hline IA-EMD (ML-TL), ms & $16.1 \pm 11.1$ & $10.5 \pm 6.4$ & $<0.05^{*}$ \\
\hline
\end{tabular}

Notes: Data are expressed as mean \pm standard deviation. $* P<0.05$.

Abbreviations: EMD, electromechanical delay; IA, interatrial; ML, mitral lateral; TL, tricuspid lateral. 
SI (OR: 4.46, 95\% CI: 1.71-11.64; $P=0.01)$, D (OR: 0.08, 95\% CI: $0.02-0.32 ; P=0.01$ ), and Ep (OR: $1.12,95 \% \mathrm{CI}$ : $1.04-1.21 ; P=0.01)$ were correlated with presence of AD. In multivariate regression analysis, using a model adjusted for age, sex, presence of hypertension, LA volumes, and interatrial EMD, D (OR: 0.09, 95\% CI: 0.02-0.41; $P=0.01)$ and Ep (OR: $1.12,95 \%$ CI: $1.02-1.23 ; P=0.02$ ) were found to be independent correlates of AD. However, age, sex, presence of hypertension, LA volume, interatrial EMD, and SI did not remain as independent correlates of the disease.

\section{Discussion}

The main findings of our study were that patients with AD have abnormal aortic stiffening compared to age- and sexmatched controls. In particular, D and Ep were independently correlated with presence of AD. Even though LV diastolic parameters and atrial conduction times in $\mathrm{AD}$ patients were significantly different from control subjects, these parameters were not independent correlates of AD.

\section{Diastolic functions and atrial conduction time}

In this study, we observed that patients with $\mathrm{AD}$ have altered diastolic function when compared to a control group. The intergroup differences of the $\mathrm{E}$ and $\mathrm{A}$ wave velocity, E/A ratio, DT, IVRT, LA volume, and atrial conduction times measured from ML and MS annuli were statistically significant. Mitral valve PW parameters were significantly different between the two groups, with lower E velocities and higher A velocities, DT, and IVRT in Alzheimer patients. Mitral annular $\mathrm{E}_{\mathrm{a}}$ velocity was significantly lower in Alzheimer patients, whereas $A_{a}$ velocity and $E / E_{a}$ ratio were similar between the groups. Our results from both the AD and control groups were consistent with borderline low $\mathrm{E}$ and borderline high A components of the diastolic filling velocities, resulting in an E/A ratio of less than 1.0. This level of diastolic relaxation impairment is consistent with the age range of our study participants. However, our findings were associated with statistically significant impairment of diastolic parameters in the AD group when compared with the ND group. Similar to our findings, Belohlavek et $\mathrm{al}^{19}$ found that patients with $\mathrm{AD}$ have altered mitral inflow parameters and vortex formation time. However, they did not evaluate for the more sensitive tissue Doppler parameters for diastolic functions that we observed in our study.

In previous studies, it was shown that $\mathrm{AD}$ was associated with vascular risk factors and cardiovascular disease process. ${ }^{5,20-23}$ Hypertension, diabetes, stroke, and atherosclerosis have been shown to increase AD risk. ${ }^{7,24,25}$ During the aging process, heart, arteries, and brain suffer the continuous cumulative consequences of hemodynamic and mechanical stresses, ${ }^{19,26-28}$ further, the myocardium undergoes structural changes including interstitial fibrosis and cellular disarray, which affects the diastolic functions negatively as a result of aging. ${ }^{29-31}$

In this study, we observed that intraventricular blood transport rheologic processes are suboptimal and altered in patients with AD. Although no causal relationship can be deduced from our data, it may be further speculated that the suboptimal hemodynamic efficiency could be the pathophysiologic link between the more pronounced LV relaxation dysfunction and ultimate brain cognitive dysfunction in patients with AD. However, these are preliminary observations and need to be taken cautiously because of the small number of patients involved in this study and the limitations in the accuracy of the clinical diagnosis of AD. These results warrant further investigation.

In addition to conventional diastolic parameters we observed that patients with AD had increased atrial conduction times. Yavuz et $\mathrm{al}^{32}$ found that atrial conduction times increase in hypertensive patients with diastolic dysfunction. Also in Yavuz et al's study, ${ }^{32}$ the atrial conduction times measured from ML and MS and also interatrial EMD were longer in the AD group, which can be associated with more impaired diastolic function.

\section{Aortic stiffness}

In our study, we observed that PP, Ep, D, and SI were correlated with presence of AD. The measurements in our study were made by conventional echocardiography, and this is the key difference of our study from others. ${ }^{10,11,28,33}$ Similar to our findings, Hanon et $\mathrm{al}^{10}$ observed that PW velocity (PWV) was significantly higher in subjects with vascular dementia or AD than in those without cognitive impairment, and they pointed out that arterial stiffness appeared to be an independent determinant not only of vascular dementia, but also of AD. A previous study by Bateman et $\mathrm{al}^{28}$ showed that early $\mathrm{AD}$ is characterized by reduced blood flow and reduced compliance. Nagai et $\mathrm{al}^{33}$ showed a relationship between PWV and cognitive decline in nonvascular dementia. In contrast to our observations, a previous study by Dhoat et al ${ }^{11}$ which compared vascular compliance and arterial stiffness between vascular dementia, AD, and control groups by measuring central arterial compliance, augmentation index, and PWV, concluded that arterial stiffness in patients with $\mathrm{AD}$ is no different from that in controls. 
Several mechanisms may explain our findings of an association between increased aortic stiffness and AD. Aortic stiffness can cause an increase in central PP, which may influence arterial remodeling at the site of the extracranial and intracranial arteries. Indeed, PP and arterial stiffness have been related to atherosclerosis or arteriosclerosis in large $\mathrm{e}^{34,35}$ and small ${ }^{36}$ vessels. An increased PP has been associated with the prevalence and severity of cerebral white matter lesions, ${ }^{37}$ and, in a recent study, aortic stiffness appeared as an independent predictor of stroke in patients with essential hypertension. ${ }^{38}$ Our study indicates an independent correlation between aortic stiffness and $\mathrm{AD}$, supporting previous studies suggesting that functional changes of the arterial system $^{10,11,28,33}$ could play a role in the pathogenesis of Alzheimer dementia.

\section{Limitations}

The main limitation of our study is small sample size. This study was a cross-sectional study without long-term follow-up, and the prognostic importance of these echocardiographic parameters is not known. Further studies with a larger sample size are needed to confirm our findings.

\section{Conclusion}

Our findings suggest that patients with $\mathrm{AD}$, the most common form of dementia, are more likely to have diastolic dysfunction and longer atrial conduction times. More importantly, our study has shown that D and Ep, which are the basic parameters of aortic stiffness, were independently correlated with presence of AD. Although we could not detect a causal relationship in this study, subclinical cardiac involvement in $\mathrm{AD}$ warrants further investigation. Further prospective studies are needed to clarify the role of these findings during disease development, progress, and management.

\section{Disclosure}

The authors report no conflicts of interest in this work.

\section{References}

1. Geldmacher DS, Whitehouse PJ. Evaluation of dementia. N Engl J Med. 1996;335:330-336.

2. Neuropathology Group. Medical Research Council Cognitive Function and Aging Study. Pathological correlates of late-onset dementia in a multicentre, community based population in England and Wales. Neuropathology Group of the Medical Research Council Cognitive Function and Ageing Study (MRC CFAS). Lancet. 2001;357:169-175.

3. Launer LJ, Ross GW, Petrovitch H, et al. Midlife blood pressure and dementia: the Honolulu-Asia aging study. Neurobiol Aging. 2000;21: $49-55$.

4. Skoog I, Lernfelt B, Landahl S, et al. 15-year longitudinal study of blood pressure and dementia. Lancet. 1996;347:1141-1145.
5. Hofman A, Ott A, Breteler MM, et al. Atherosclerosis, apolipoprotein E, and prevalence of dementia and Alzheimer's disease in the Rotterdam Study. Lancet. 1997;349:151-154.

6. Ott A, Stolk RP, van Harskamp F, Pols HA, Hofman A, Breteler MM. Diabetes mellitus and the risk of dementia: the Rotterdam Study. Neurology. 1999;53:1937-1942.

7. Honig LS, Tang MX, Albert S, et al. Stroke and the risk of Alzheimer disease. Arch Neurol. 2003;60:1707-1712.

8. de la Torre JC. Alzheimer's disease prevalence can be lowered with non-invasive testing. J Alzheimer Dis. 2008;14:353-359.

9. Rabkin SW, Jarvie G. Comparison of vascular stiffness in vascular dementia, Alzheimer dementia and cognitive impairment. Blood Press. 2011;20:274-283.

10. Hanon $\mathrm{O}$, Haulon S, Lenoir H, et al. Relationship between arterial stiffness and cognitive function in elderly subjects with complaints of memory loss. Stroke. 2005;36:2193-2197.

11. Dhoat S, Ali K, Bulpitt CJ, Rajkumar C. Vascular compliance is reduced in vascular dementia and not in Alzheimer's disease. Age Ageing. 2008;37:653-659.

12. Reitz C, Brickman AM, Luchsinger JA, Wu WE, Small SA, Tang MX. Frequency of subclinical heart disease in elderly persons with dementia. Am J Geriatr Cardiol. 2007;16:183-188.

13. McKhann G, Drachman D, Folstein M, Katzman R, Price D, Stadlan EM. Clinical diagnosis of Alzheimer's disease: report of the NINCDSADRDA Work Group under the auspices of Department of Health and Human Services Task Force on Alzheimer's Disease. Neurology. 1984;34:939-944.

14. American Psychiatric Association. Diagnostic and Statistical Manual of Mental Disorders, Fourth Edition. Washington, DC: American Psychiatric Association; 1994.

15. Lang RM, Bierig M, Devereux RB, et al; Chamber Quantification Writing Group; American Society of Echocardiography's Guidelines and Standards Committee; European Association of Echocardiography. Recommendations for chamber quantification: a report from the American Society of Echocardiography's Guidelines and Standards Committee and the Chamber Quantification Writing Group, developed in conjunction with the European Association of Echocardiography, a branch of the European Society of Cardiology. J Am Soc Echocardiogr. 2005;18(12):1440-1463.

16. Stefanadis C, Stratos C, Boudoulas H, Kourouklis C, Toutouzas P. Distensibility of the ascending aorta: comparison of invasive and noninvasive techniques in healthy men and in men with coronary artery disease. Eur Heart J. 1990;11:990-996.

17. Dernellis J, Panaretou M. Aortic stiffness is an independent predictor of progression to hypertension in nonhypertensive subjects. Hypertension. 2005;45:426-431.

18. Nemes A, Geleijnse ML, Forster T, Soliman OI, Ten Cate FJ, Csanády M. Echocardiographic evaluation and clinical implications of aortic stiffness and coronary flow reserve and their relation. Clin Cardiol. 2008; 31:304-309.

19. Belohlavek M, Jiamsripong P, Calleja AM, et al. Patients with Alzheimer disease have altered transmitral flow: echocardiographic analysis of the vortex formation time. J Ultrasound Med. 2009;28(11):1493-1500.

20. Barnes DE, Yaffe K. The projected effect of risk factor reduction on Alzheimer's disease prevalence. Lancet Neurol. 2011;9:819-828.

21. Korczyn AD. The underdiagnosis of the vascular contribution to dementia. J Neurol Sci. 2005;229-230:3-6.

22. Luchsinger JA, Mayeux R. Cardiovascular risk factors and Alzheimer's disease. Curr Atheroscler Rep. 2004;6(4):261-266.

23. Stefanova E, Pavlovic A, Jovanovic Z, et al. Vascular risk factors in Alzheimer's disease - preliminary report. J Neurol Sci. 2012;322(1-2): 166-169.

24. Luchsinger JA, Tang MX, Stern Y, Shea S, Mayeux R. Diabetes mellitus and risk of Alzheimer's disease and dementia with stroke in a multiethnic cohort. Am J Epidemiol. 2001;154(7):635-641.

25. Posner HB, Tang MX, Luchsinger J, Lantigua R, Stern Y, Mayeux R. The relationship of hypertension in the elderly to $\mathrm{AD}$, vascular dementia, and cognitive function. Neurology. 2002;58(8):1175-1181. 
26. Maalikjy Akkawi N, Borroni B, Agosti C, et al. Volume reduction in cerebral blood flow in patients with Alzheimer's disease: a sonographic study. Dement Geriatr Cogn Disord. 2003;16(3):163-169.

27. Ruitenberg A, den Heijer T, Bakker SL, et al. Cerebral hypoperfusion and clinical onset of dementia: the Rotterdam Study. Ann Neurol. 2005; 57:789-794.

28. Bateman GA, Levi CR, Schofield P, Wang Y, Lovett EC. Quantitative measurement of cerebral haemodynamics in early vascular dementia and Alzheimer's disease. J Clin Neurosci. 2006;13:563-568.

29. Masugata H, Senda S, Goda F, et al. Cardiac function as assessed by echocardiography in the oldest old $>$ or $=90$ years of age. Int Heart J. 2007;48:497-504.

30. Burlew BS. Diastolic dysfunction in the elderly - the interstitial issue. Am J Geriatr Cardiol. 2004;13:29-38.

31. Villari B, Vassalli G, Schneider J, Chiariello M, Hess OM. Age dependency of left ventricular diastolic function in pressure overload hypertrophy. J Am Coll Cardiol. 1997;29:181-186.

32. Yavuz B, Abali G, Ciftci O, et al. Atrial electromechanical delay gets longer in hypertensive patients with diastolic dysfunction. 2nd Annual Congress on Update in Cardiology and Cardiovascular Surgery. Clinical Cardiology. 2006;29 Supp1 3:01:21
33. Nagai K, Akishita M, Machida A, Sonohara K, Ohni M, Toba K. Correlation between pulse wave velocity and cognitive function in nonvascular dementia. J Am Geriatr Soc. 2004;52:1037-1038.

34. Boutouyrie P, Bussy C, Lacolley P, Girerd X, Laloux B, Laurent S. Association between local pulse pressure, mean blood pressure, and large-artery remodeling. Circulation. 1999;100:1387-1393.

35. van Popele NM, Grobbee DE, Bots ML, et al. Association between arterial stiffness and atherosclerosis: the Rotterdam Study. Stroke. 2001; 32:454-460.

36. Baumbach GL, Siems JE, Heistad DD. Effects of local reduction in pressure on distensibility and composition of cerebral arterioles. Circ Res. 1991;68:338-351.

37. Liao D, Cooper L, Cai J, et al. The prevalence and severity of white matter lesions, their relationship with age, ethnicity, gender, and cardiovascular disease risk factors: the ARIC Study. Neuroepidemiology. 1997; 16:149-162.

38. Laurent S, Katsahian S, Fassot C, et al. Aortic stiffness is an independent predictor of fatal stroke in essential hypertension. Stroke. 2003;34 1203-1206.
Clinical Interventions in Aging

\section{Publish your work in this journal}

Clinical Interventions in Aging is an international, peer-reviewed journal focusing on evidence-based reports on the value or lack thereof of treatments intended to prevent or delay the onset of maladaptive correlates of aging in human beings. This journal is indexed on PubMed Central, MedLine,

\section{Dovepress}

CAS, Scopus and the Elsevier Bibliographic databases. The manuscript management system is completely online and includes a very quick and fair peer-review system, which is all easy to use. Visit http://www.dovepress. com/testimonials.php to read real quotes from published authors. 